\title{
Fortification of sulfited tannin from the bark of Acacia mangium with phenol- formaldehyde for use as plywood adhesive
}

\begin{abstract}
The Acacia mangium tree contains $10 \%$ bark (v/v), of which about $20 \%$ are extractives. Extraction of this bark using a combination of water and sulfite medium can produce between $15 \%$ and $25 \%$ tannin materials (dry weight). In this work, several extraction conditions such as bark size, plantation site, extraction time and extraction medium were studied. The results showed that by using either hot water or a sulfite medium, a reasonable amount of tannin yield can be obtained. Bark size of less than 1-mm mesh size gave relatively high tannin yield irrespectively of the extraction medium used. Using a 600:100:2:0.5 (w/w) ratio of water:bark:sodium sulfite:sodium carbonate, and reacted at $75^{\circ} \mathrm{C}$ for $3 \mathrm{~h}$ improved the tannin yield by at least $30 \%$. The extracts were reasonably reactive towards formaldehyde as shown by their high Stiasny number; water extract, 60-70\% and aqueous sulfite-carbonate extracts, 85-90\%. The gluing results showed that the shear strength of the plywood can meet the requirements of the European Standards EN 314-1 and EN 314-2:1993. Incorporation of low molecular weight PF resin (10 parts) and PF (10 parts) improved the shear strength from 0.96 $\mathrm{MPa}$ to $1.43 \mathrm{MPa}$ after a $72 \mathrm{~h}$ boiling test. This study showed that A. mangium tannin blended with commercial plywood phenol-formaldehyde resin, low molecular weight PF and paraformaldehyde as a cross-linker can be used to bond Kedondong (Canarium spp.) wood veneers suitable for both interior and exterior grade plywood.
\end{abstract}

Keyword: Tannin, Acacia mangium, Sulfite tannin, Plywood, Phenol-formaldehyde, Shear strength 